\title{
$O$ atendimento da crise nos diversos componentes da rede de atenção psicossocial em Natal/RN
}

The crisis attention in the various components of psychosocial care network in Natal / RN Atención a la crisis en los diversos componentes de la red de atención psicosocial en Natal/RN

\section{Magda Dimenstein}

Universidade Federal do Rio Grande do Norte, Natal, RN, Brasil.

Ana Karenina Arraes Amorim

Universidade Federal do Rio Grande do Norte, Natal, RN, Brasil.

\section{Jader Leite}

Universidade Federal do Rio Grande do Norte, Natal, RN, Brasil.

\section{Kamila Siqueira}

Universidade Federal do Rio Grande do Norte, Natal, RN, Brasil.

\section{Viktor Gruska}

Universidade Federal do Rio Grande do Norte, Natal, RN, Brasil.

\section{Clarisse Vieira}

Universidade Federal do Rio Grande do Norte, Natal, RN, Brasil.

Cecília Brito

Universidade Federal do Rio Grande do Norte, Natal, RN, Brasil.

\section{Ianny Medeiros}

Universidade Federal do Rio Grande do Norte, Natal, RN, Brasil.

\section{Maria Clara Bezerril}

Universidade Federal do Rio Grande do Norte, Natal, RN, Brasil.

\section{Resumo}

O atendimento da crise é um dos problemas mais evidentes e de difícil manejo na atualidade. Além disso, é um dos eixos estratégicos e pilar de sustentação da reforma psiquiátrica. Em função disso realizamos uma investigação com o objetivo conhecer a configuração, funcionamento e modos de acolhimento na RAPS de Natal-RN. Entrevistamos 137 profissionais e gestores vinculados aos CAPS, SAMU, UPAs, Hospitais Gerais e Hospital Psiquiátrico. Identificamos diversos pontos de estrangulamento: número limitado de serviços que acolhem urgências; falta de comunicação entre equipes dos diferentes componentes; 
ausência de matriciamento com a atenção primária e de leitos de atenção integral nos hospitais gerais. Consideramos que o município apresenta capacidade limitada de responder às situações de crise e demandas emergenciais, a qual depende de uma boa articulação entre os componentes da RAPS e destes com os demais serviços de saúde, especialmente de urgência e emergência, da presença efetiva de leitos de atenção integral, além de integração eficaz com a rede de suporte social.

Palavras-chave: Reforma Psiquiátrica, Saúde Mental, Crise, Rede de Atenção Psicossocial

\begin{abstract}
The crisis' treatment is one of the most evident problems in our days, and also one of the hardest to fix. Besides that, it's one of the pillars of the psychiatrical reform. Taking that in consideration, we realized an investigation with the objective of knowing the configuration, the operation and the ways of reception at the RAPS of Natal-RN. We interviewed 137 professionals connected to the following institutions: CAPS, SAMU, UPAs, Hospitais Gerais and Hospital Psiquiátrico. We identified many points strangulation: the limited number of services that concern to the urgent care, the lack of communication between the workingteams, the absence of specialist orientation in primary care and the lack of beds for full time caring in the general hospitals. We consider that the city presents a limited capacity to respond to a crisis situations and emergencial demands, that depend on a good articulation between the components of the RAPS and the other ones with the health system, specially the emergency ones, the effective presence of beds for full time care, and of the proper integration with the social support network.
\end{abstract}

Keywords: Psychiatric Reform, Mental Health, Crisis, Psychosocial Care Network.

\title{
Resumen
}

La atención a la crisis es uno de los problemas más evidentes y difíciles de manejar en salud mental. Además, es uno de los pilares estratégicos de la reforma psiquiátrica. Esta investigación fue hecha con el objetivo de conocer la configuración, modos de funcionamiento y de acogida en la RAPS de la ciudad de Natal, Brasil. Hemos entrevistado a 137 directivos y profesionales vinculados al CAPS, SAMU, UPAS, hospitales generales y hospital psiquiátrico. Se identificaron varios problemas: número limitado de servicios de emergencia, falta de comunicación entre los equipos de los diferentes componentes, ausencia de articulacion con la atención primaria y de camas de psiquiatria en los hospitales generales. Creemos que el municipio tiene una capacidad limitada para responder a las crisis y las 
demandas de emergencia, que depende de una buena relación entre los componentes de la RAPS y con otros servicios de salud, especialmente las salas de emergencia, la presencia efectiva de camas atención integral y efectiva integración con la red de apoyo social.

Palabras clave: Reforma Psiquiátrica, Crisis, Salud Mental, Red de Atención Psicosocial.

Introdução

O atendimento da crise é um dos problemas mais evidentes e de difícil manejo para as equipes de saúde mental na atualidade. Segundo Souza (2012) ${ }^{1}$

\section{(...) este desafio "não é somente uma prioridade estratégica, mas funciona como um analisador dos processos de Reforma Psiquiátrica. Analisa a sua amplitude e capacidade de resposta ao sofrimento mental, num sentido quantitativo e a sua consistência política em termos de capacidade de desinstitucionalização (p.2).}

A substituição do modo asilar implica na estruturação de uma rede articulada de serviços que abarquem as diferentes necessidades da pessoa em sofrimento psíquico, especialmente nos momentos de crise. Nosso desafio está em melhorar a qualidade técnica, a equidade e a continuidade da atenção em relação às pessoas com transtornos mentais graves e persistentes, com o objetivo de reduzir suas consequências e proporcionar

\footnotetext{
${ }^{1}$ Texto acessível em: http://xa.yimg.com/kq/groups/22370896/13303633 27/name/Servico_de_Urgencia_Psiquiatrica\%5B1 $\% 5$ D.pdf
} possibilidades de reinserção social. Em função disso, desenvolvemos uma pesquisa $^{2}$ objetivando conhecer a configuração, funcionamento e modos de acolhimento produzidos nos diversos componentes da rede de atenção psicossocial/RAPS de Natal-RN.

No Brasil, o atendimento da crise só vem sendo alvo de preocupação há poucos anos. Não observamos esforços no sentido de estabelecer critérios claros e/ou regulamentação adequada para garantir acesso a uma atenção de qualidade respeitando os direitos dos usuários. Neste sentido, essa pesquisa cumpre a função de gerar conhecimento que possa subsidiar mudanças e novos direcionamentos para a Política Nacional de Saúde Mental/PNSM e organização da Rede de Atenção Psicossocial/RAPS. É preciso investir não só na desconstrução do paradigma manicomial que sustenta as práticas de atenção nesse campo, mas especialmente, na reorganização de uma rede de cuidados que articule a rede SUS como um todo e,

\footnotetext{
2 Pesquisa intitulada: Rede de Atenção Integral à Crise e Estratégias de Acolhimento com Classificação de Risco em Saúde Mental. Foi aprovada pelo CEP (protocolo 330/09) e financiada pelas agências de fomento CNPq (Edital Ciências Humanas e Sociais/2010) e FAPERN (PPSUS III).
} 
nesse sentido, o CAPS III, os hospitais gerais e de emergência, bem como o Serviço de Atenção Móvel de Urgência/SAMU ProntoAtendimentos/UPAs, têm lugar de destaque.

\section{Percurso Metodológico}

Nosso percurso metodológico consistiu de diferentes etapas desenvolvidas ao longo de 24 meses (Agosto de 2010 a Julho de 2012). Teve início com os contatos institucionais com as gestões estadual e municipal de saúde e saúde mental no sentido de definir os locais e pactuar calendário da pesquisa de campo. Depois de estabelecidos os acordos, procedemos às visitas aos serviços substitutivos, hospitais de urgência e emergência, prontoatendimentos, SAMU e Hospital Psiquiátrico João Machado, para mapear as equipes presentes nessas instituições e fazer um levantamento da disponibilidade dos técnicos para participação na pesquisa. Trabalhamos com dois roteiros de entrevistas semiestruturadas: um para gestores e outro para trabalhadores. Os eixos temáticos das entrevistas versaram sobre: estratégia da atenção psicossocial; rede de cuidados; atenção à crise; gestão; formação profissional; processos de trabalho em saúde. Para melhor operacionalização da coleta de dados, estabelecemos três etapas de imersão na rede de serviços de saúde local.

\begin{tabular}{|c|c|c|}
\hline $\begin{array}{l}\text { ETAPAS DA COLETA DE } \\
\text { DADOS }\end{array}$ & SERVIÇOS PESQUISADOS & $\begin{array}{l}\text { ENTREVISTAS } \\
\text { REALIZADAS } \\
(\mathbf{n}=\mathbf{1 3 7})\end{array}$ \\
\hline $\begin{array}{l}\text { ETAPA I }(\mathbf{n}=\mathbf{6 3}) \\
\text { Serviços da RAPS }\end{array}$ & $\begin{array}{l}01 \text { CAPS III, } \\
01 \text { CAPS II/Oeste } \\
01 \text { CAPS ad/Norte } \\
01 \text { CAPS ad/Leste }\end{array}$ & $\begin{array}{l}27 \\
13 \\
12 \\
11\end{array}$ \\
\hline $\begin{array}{l}\text { ETAPA II }(\mathbf{n}=\mathbf{4 1}) \\
\text { Rede de Pronto-Atendimento } \\
\text { e SAMU }\end{array}$ & $\begin{array}{l}\text { UPA- Pajuçara } \\
\text { UPA- Mãe Luísa } \\
\text { UPA- Satélite } \\
\text { SAMU }\end{array}$ & $\begin{array}{l}12 \\
11 \\
12 \\
06\end{array}$ \\
\hline $\begin{array}{l}\text { ETAPA III }(\mathbf{n}=\mathbf{3 3}) \\
\text { Rede hospitalar de urgência e } \\
\text { emergência e Hospital } \\
\text { psiquiátrico }\end{array}$ & $\begin{array}{l}\text { Hospital Universitário Onofre Lopes/HUOL } \\
\text { Hospital Pedro Bezerra/Santa Catarina } \\
\text { Hospital Monsenhor Walfredo Gurgel } \\
\text { Hospital Psiquiátrico Dr. João Machado/HJM }\end{array}$ & $\begin{array}{l}09 \\
10 \\
05 \\
09\end{array}$ \\
\hline
\end{tabular}


Quadro 1 - Etapas da coleta de dados

Fonte: Dados da pesquisa

As entrevistas foram realizadas nos serviços de saúde durante o ano de 2011 com todos os profissionais que se dispuseram a participar da pesquisa, após assinatura do Termo de Consentimento Livre e Esclarecido. Não houve delimitação prévia de número e categoria profissional. A estratégia foi visitar cada serviço quantas vezes fossem necessárias para atingir um maior número de participantes, contemplando os diferentes turnos dos mesmos.

\section{Atendimento Da Crise:}

\section{O Cenário Da Saúde Mental No}

\section{Contexto Nacional E Local}

\begin{abstract}
As doenças crônicas não transmissíveis (DCNT) se tornaram a principal prioridade na área da saúde no Brasil - $72 \%$ das mortes ocorridas em 2007 foram atribuídas a elas. As DCNT são a principal fonte da carga de doença e os transtornos neuropsiquiátricos detêm a maior parcela de contribuição (Schmidt et al, 2011, p.61).
\end{abstract}

Esses dados foram publicados recentemente pela revista The Lancet acerca da Saúde no Brasil. A Organização Mundial da Saúde/OMS, na $65^{\text {a }}$ Assembleia Mundial de Saúde ocorrida em maio de 2012, reconheceu que além dos danos à saúde, há consequências sociais e econômicas de longo alcance e por isso recomendou aos Estados membros,

\begin{abstract}
a que, según las prioridades nacionales y en el marco de sus contextos específicos, elaboren y refuercen políticas y estrategias integrales referentes a la promoción de la salud mental, la prevención de los trastornos mentales, y la identificación temprana, la atención, el apoyo, el tratamiento y la recuperación de las personas con trastornos mentales (Organización Mundial de la Salud, 2011, p.3).
\end{abstract}

Apesar de todo o empenho, há certa invisibilidade ou desconhecimento em nível nacional acerca da gravidade e do impacto que os transtornos mentais provocam, especialmente, a depressão, as psicoses e os transtornos atribuíveis ao uso inadequado do álcool, responsáveis pela maior parte da carga de adoecimento e mortalidade. Nesse contexto, o atendimento da crise ganha bastante relevo. Diversos países têm se preocupado em elaborar propostas de intervenção para esses momentos críticos por considerar que a rapidez da atenção e a forma de manejo dessas situações são decisivas para dar uma resposta eficaz e assim evitar hospitalizações, sofrimento e, por consequência, cronificação. Dessa forma, o 
tipo de abordagem dirigida à crise pode ser um fator de proteção se "ayudar al paciente a estabilizar y reajustar su situación psicopatológica y a posibilitar la recuperación de su nivel de funcionamento" (Comunidad DE Madrid, 2012, p.16). Estamos de acordo com Souza (2012) que

a resposta às crises dos portadores de sofrimento mental grave e persistente tem sido apontada como um dos principais desafios da Reforma Psiquiátrica na medida em que é condição essencial para dar sustentação ao conjunto de iniciativas no campo da assistência/cuidado e reabilitação psicossocial destes sujeitos, tendo em vista as suas demandas e exigências políticas de cidadania. Este desafio não é somente uma prioridade estratégica, mas funciona como um analisador dos processos de Reforma Psiquiátrica. Analisa a sua amplitude e capacidade de resposta ao sofrimento mental, num sentido quantitativo e, a sua consistência política em termos de capacidade de desinstitucionalização (p.02).

Conforme a Política de Saúde Mental brasileira move-se em direção ao fornecimento de cuidados integrais a usuários em sofrimento psíquico, tornamse necessários a ampliação dos entendimentos acerca da crise e a elaboração de formas eficazes para seu manejo nos hospitais gerais e de emergência, Pronto-Atendimentos, CAPS III e SAMU. Hoje, podemos observar uma expansão e interiorização dos diversos serviços que compõem a RAPS pelo país e a consequente diminuição no número de leitos (passou de 39.567 em 2006 para 32.735 em 2010) e de internações em hospitais psiquiátricos (Brasil, 2011). Apesar dessa ampliação que indica o avanço do processo de reforma psiquiátrica brasileira é preciso promover ações que garantam o acesso com qualidade, trabalhar de forma georeferenciada, ofertar cuidados considerando a diversidade das necessidades dos usuários e garantir a participação dos mesmos nos processos decisórios. Nesse cenário, o problema do atendimento da crise emerge como um dos principais entraves ao aprofundamento das mudanças em curso.

Além do estigma e preconceitos associados ao portador de transtornos mentais e dos problemas relacionados aos processos de trabalho em saúde, especificamente em termos do cuidado a essa clientela, outros obstáculos se impõem à reestruturação da RAPS, em especial a integração da rede hospitalar geral e a completa substituição do aparato manicomial. Atualmente, é indiscutível a necessidade de termos serviços em rede que operem na perspectiva da continuidade de cuidados, gestão integrada de casos e corresponsabilização. Sabemos que criar articulações com a rede de atenção primária, fortalecendo seu potencial no 
acolhimento às demandas em saúde mental, bem como com os serviços de urgência e emergência e hospitais gerais, é uma das principais ações para termos resultados mais efetivos no atendimento da crise. Ademais, precisamos definir critérios claros, levando em conta o que as legislações internacionais recomendam acerca das situações de crise e emergência, dos procedimentos para admissão e tratamento involuntários, bem como sobre os direitos dos usuários.

No entanto, o que observamos no cenário nacional e local é uma evidente fragilidade em diversos componentes da RAPS e das propostas de avanço acima referenciadas. Dos 1.620 CAPS existentes no país apenas 55 são do tipo III, dos quais o Rio Grande do Norte, incluindo a capital, possui apenas 01. Em relação à Atenção Primária, diversos estudos realizados nacionalmente, assim como em Natal, apontam as dificuldades em relação à implantação do matriciamento e ao desenvolvimento de ações compartilhadas pelas equipes da Estratégia de Saúde da Família/ESF, dos Núcleos de Apoio à Saúde da Família/NASF e dos serviços substitutivos, nos territórios de vinculação dos usuários. Observa-se que o número de equipes de NASF no país ainda é reduzido, e em Natal ele se limita a três (03) equipes, indicando a precária capacidade de cobrir as necessidades crescentes de suporte em saúde mental apresentadas pelas equipes da ESF.

Por outro lado, o modo de funcionamento do SAMU e a fragilidade da participação do hospital geral no processo de reforma psiquiátrica configuram-se como poderosos obstáculos. Em estudo anterior sobre a urgência psiquiátrica (Jardim \& Dimenstein, 2007), indicamos que a formatação dos serviços de urgência e emergência impossibilita a formação de vínculo, visto que são pontuais, ignoram a complexidade do sofrimento, simplificando-o por meio da atenção ao sintoma, retira do indivíduo a responsabilidade sobre o seu estado e a sua vida, inserindo-o em um cotidiano artificial isolado, roubam sua autonomia, desconsideram a potencialidade da crise enquanto movimento de mudança e transformação.

Apesar da portaria 2048/GM que atesta que as urgências psiquiátricas são de competência técnica dos serviços de urgência (Brasil, 2003), localizando o SAMU como uma porta de entrada itinerante capaz de fazer potentes articulações inter-redes (Jardim \& Dimenstein, 2007), nota-se uma enorme resistência dos SAMUs no país inteiro em prestar socorro; se recusam a atender os casos de pessoas em sofrimento mental agudo ou, mais grave ainda, a utilização corrente de procedimentos que trazem a 
marca dos métodos clássicos empregados costumeiramente pelos hospitais psiquiátricos, bastante semelhantes à tortura, como a imobilização mecânica usada como punição (Jardim \& Dimenstein, 2008).

Importante destacar que a Política Nacional de Saúde Mental vem trabalhando nos últimos anos com o conceito de leitos de atenção integral em saúde mental, presentes em hospitais gerais, CAPS III, emergências gerais e serviços hospitalares de referência para álcool e drogas. Apesar desse fomento, existia até final de 2010 apenas 3.371 leitos psiquiátricos do SUS em hospitais gerais em um cenário de redução significativa de leitos em hospitais psiquiátricos, tal como no período de 2007 a 2010, quando se registrou uma redução de 6.832 leitos psiquiátricos no país (Brasil, 2011). Dessa forma, a expansão do número de leitos qualificados para a atenção a saúde mental em Hospitais Gerais foi considerado insatisfatório em todo território nacional nos últimos anos, além do que "a criação desses leitos psiquiátricos no Brasil não obedeceu a qualquer planejamento de cobertura populacional" (Pitta, 2011, p.4581).

Tais fatos vêm produzindo espaços lacunares na atenção ao usuário em crise, vazios para os quais a principal resposta da RAPS, especialmente em Natal, tem sido o encaminhamento ao hospital psiquiátrico. Em outras palavras, as dificuldades de fechamento de hospitais psiquiátricos no país devem-se, em grande parte, à ineficiência de serviços que deem suporte à crise. Assim, os manicômios continuam ocupando um lugar central em função na inexistência desses dispositivos e tendo sua existência justificada socialmente.

Atualmente em Natal, dispomos de uma Rede de Atenção Psicossocial/RAPS claramente precarizada. Estão em funcionamento um CAPS II e um CAPS III. A rede possui também dois CAPSad, um CAPSi, um ambulatório de saúde mental, um Ambulatório de Prevenção e Tratamento de Tabagismo, Alcoolismo e outras drogas e dois serviços residenciais terapêuticos. Não dispomos de leitos de atenção integral nos hospitais gerais e de emergência, apenas 06 leitos em ala psiquiátrica localizada no Hospital Universitário Onofre Lopes/HUOL, não há centro de convivência e cultura, casas de acolhimento transitório, e muito menos de uma articulação eficaz com a rede básica de saúde. Ademais, contabiliza-se um total de 717 leitos psiquiátricos no Estado, sendo que 532 estão concentrados na capital $^{3}$. Segundo dados do DATASUS ${ }^{4}$,

http://tabnet.datasus.gov.br/cgi/tabcgi.exe?cnes/cnv /leiintrn.def

Acesso em 12 de setembro de 2012 
no período de janeiro de 2011 a junho de 2012, foram registrados 3.064 internações psiquiátricas em Natal, muitas das quais poderiam ter sido evitadas ou acolhidas na rede extra-hospitalar e/ou de hospitais gerais. Portanto, a precariedade e desarticulação da rede assistencial no município são uma evidência e um problema com o qual precisamos nos preocupar e investir na formulação de estratégias visando à efetivação dos princípios da integralidade, resolutividade, a intersetorialidade das políticas e uma atuação territorial.

\section{Perfil dos Técnicos e Gestores de Saúde Participantes da Investigação}

$\begin{array}{lcccr}\text { Os } & \text { participantes } & \text { da } & \text { nossa } \\ \text { investigação } & \text { constaram } & \text { de } & 137 \\ \text { profissionais } & \text { vinculados à } & \text { RAPS } & \text { do } \\ \text { município } & \text { de } & \text { Natal/RN, } & & \text { lotados } \\ \text { especificamente } & \text { em } & \text { serviços } & \text { do } & \text { tipo }\end{array}$
CAPS, SAMU, Pronto-Atendimento, Hospitais Gerais e Psiquiátrico. Desses, 121 exerciam função técnica e 16 estavam na gestão das referidas instituições. Registramos uma variedade de categorias profissionais dentre os entrevistados, embora $80 \%$ estejam concentrados nas

http://tabnet.datasus.gov.br/cgi/tabcgi.exe?sih/cnv/s $\underline{\text { xrn.def }}$

Acesso em 11 de setembro de 2012. seguintes categorias: Enfermagem, Medicina, Técnico de Enfermagem e Psicologia. Essa configuração das equipes da rede local não difere da encontrada na realidade brasileira como um todo.

Outro aspecto identificado na pesquisa diz respeito à distribuição da força de trabalho em saúde por idade e sexo, bem como quanto ao regime de contratação e vínculos de trabalho. Percebemos que a maioria dos nossos participantes é de mulheres, jovens, com média de idade entre 33 e 40 anos, concursada e com vários vínculos empregatícios. Estudos nacionais (Brito, 2000; Silva, Rotemberg \& Fischer, 2011; Luiz \& Bahia, 2009) demonstram que a saúde pública tem se tornado um espaço de concentração de trabalho feminino e assalariado (Lopes \& Leal, 2012). Ou seja, temos observado no país uma feminização do cuidado em saúde, bem como o fato do trabalho assalariado se constituir a principal forma de inserção de muitas categorias, dentre as quais destacamos a enfermagem e a psicologia, tradicionalmente femininas. Esses estudos também mostram que pelo fato da precariedade ter sempre estado associada ao trabalho feminino, nota-se que questões como remuneração, condições de trabalho, dentre outras, apresentam-se problemáticas quando se trata da saúde pública. Em função disso, observa-se a busca por mais 
de um vínculo de trabalho, de forma a garantir uma remuneração considerada justa e adequada às necessidades. Quanto às instituições formadoras, $\mathrm{o}$ grande percentual é de profissionais egressos das instituições de ensino federais $(\mathrm{n}=82)$ tais como Universidade Federal do Rio Grande do Norte/UFRN, Universidade Federal da Paraíba/UFPB e de Campina Grande/UFCG, mas já se observa a presença de instituições privadas locais como formadoras da mão de obra em saúde no estado. Nota-se que muitos profissionais apresentam formação pósgraduada em diferentes níveis.

\section{Configuração e Funcionamento da} RAPS no Atendimento da Crise

\section{a. Organização da rede}

Para contextualizar o conjunto de dados obtidos nesta investigação, é imprescindível conhecer o desenho da rede de atendimento da crise que articula CAPS, SAMU, UPAS, Hospitais Gerais, Hospital Psiquiátrico, no município de Natal/RN, no que se refere à sua localização geográfica, aos equipamentos e estruturas existentes, bem como aos fluxos identificados entre tais instituições. Abaixo, os serviços pesquisados distribuídos por bairros da capital potiguar.

\begin{tabular}{l|l|}
\hline Serviço de Saúde & Bairro \\
\hline 01 CAPS III, & Petrópolis \\
01 CAPS II/Oeste & Lagoa Nova \\
01 CAPS ad/Norte & Potengi \\
01 CAPS ad/Leste & Tirol \\
\hline UPA- Pajuçara & Pajuçara \\
UPA- Mãe Luísa & Mãe Luísa \\
UPA-Satélite & Cidade \\
\hline SAMU & Satélite \\
\hline $\begin{array}{l}\text { Hospital Universitário } \\
\text { Onofre Lopes/HUOL }\end{array}$ & $\begin{array}{l}\text { Petrópolis } \\
\text { Hospital Potengi }\end{array}$ \\
\hline $\begin{array}{l}\text { Bezerra/Santa Catarina } \\
\text { Hospital } \\
\text { Walfredo Gurgel Monsenhor }\end{array}$ & $\begin{array}{l}\text { Tirol } \\
\text { Hospital Psiquiátrico Dr. } \\
\text { João Machado/HJM }\end{array}$ \\
\hline
\end{tabular}

Quadro 2 - Distribuição dos serviços por bairro

Fonte: Dados da pesquisa

$\mathrm{Na}$ sequência, apresentamos a distribuição desses serviços por Distrito Sanitário de Saúde. 


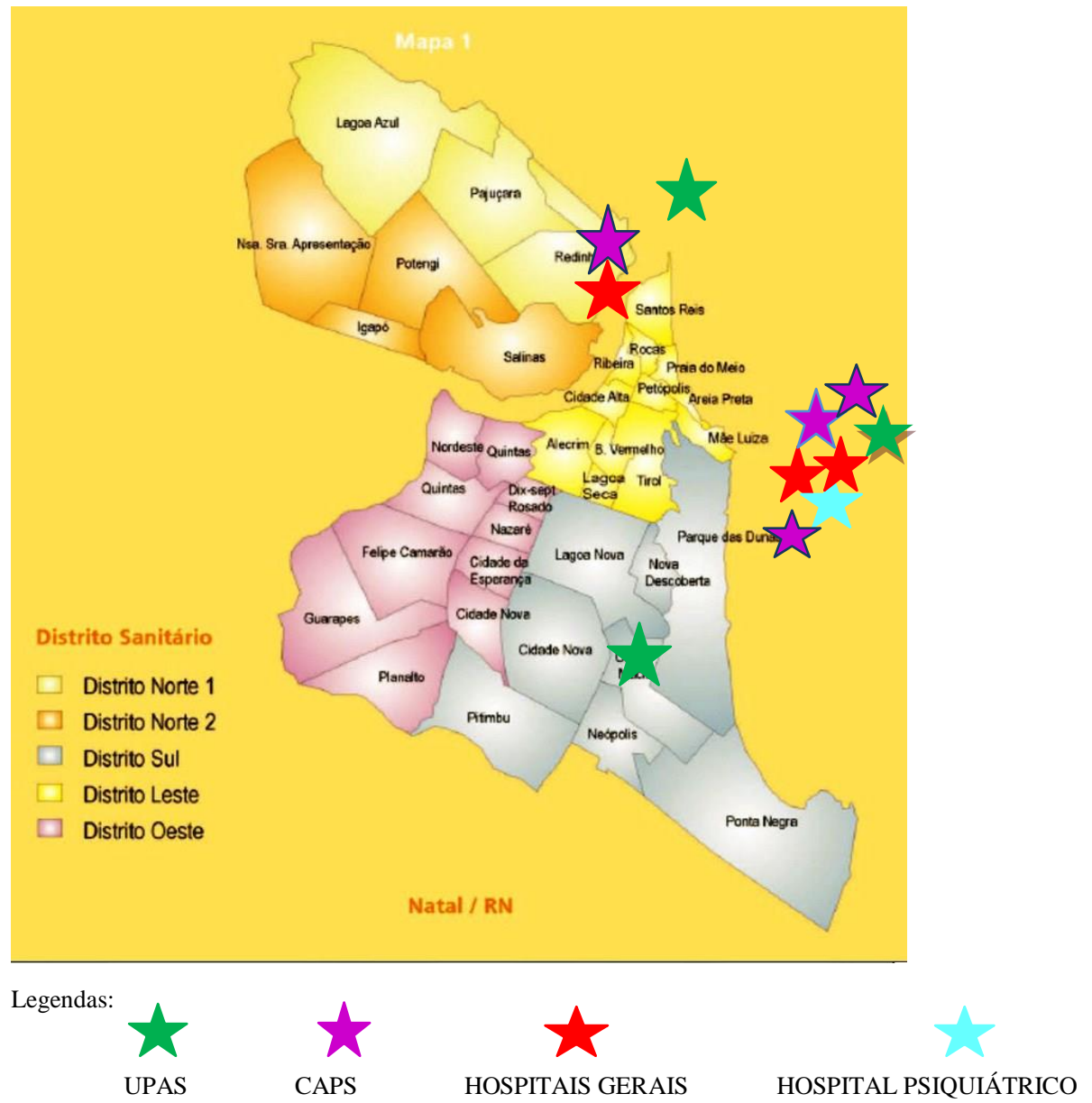

Figura 1 - Serviços de Saúde por Distrito Sanitário Fonte: Dados da Pesquisa

Observando o mapa acima é possível identificar, à primeira vista, uma concentração dos componentes que compõem a rede de atendimento da crise em uma área determinada da capital: a zona leste. Essa área é a menos populosa de Natal, a que apresenta melhores condições de infraestrutura urbana, transporte, de saneamento básico, índices epidemiológicos, serviços de saúde público e privados, ou seja, é a que é ocupada pelas classes média-alta e alta de Natal. Isso tem consequências importantes. Vejamos por que.

A modelagem das redes de atenção à saúde, segundo Mendes (2007), precisa levar em consideração alguns elementos. Em primeiro lugar, deve-se ter clara a população usuária, em seguida, os serviços disponíveis e, por fim, o modelo de atenção à saúde que articula pessoas e equipamentos. Para esse autor, é necessário utilizar variáveis como perfil demográfico e epidemiológico da população para a 
definição do modelo de atenção e para a estruturação das redes de atenção à saúde.

A configuração observada em Natal demonstra alguns pontos de estrangulamento. Em primeiro lugar, há um reduzido número de serviços que prestam atendimento da crise. Segundo, a estruturação da rede não levou em conta o perfil demográfico e epidemiológico da população para a abertura dos CAPS e das UPAS. Assim, a localização geográfica de quase todos os serviços dificulta o acesso para a maioria dos usuários que frequenta os serviços de saúde do SUS, os quais são oriundos, principalmente, da zona norte da cidade, área que apresenta perfil sócio demográfico e epidemiológico claramente distinto. Isso significa que se trabalha por oferta e não de acordo com o princípio da territorialização e população de referência, aspecto que vai totalmente de encontro à proposta de construir redes integradas, solidárias, responsivas e resolutivas. Em terceiro lugar, não existem de unidades de saúde tipo CAPS III nas demais regiões da cidade, deixando a população sem retaguarda, obrigada a recorrer ao hospital psiquiátrico, que é o centro de comunicação da rede e concentra as demandas de todas as áreas da cidade.

Mesmo com a existência de um hospital geral e uma UPA na zona norte, como veremos adiante, esses serviços não atendem situações de crise como deveriam operar, redirecionando os casos para o HJM. A função de atendimento dos casos graves e das crises pelos CAPS II ainda não foi incorporada ou não há consenso sobre isso em muitos serviços. Se as redes de atenção à saúde são constituídas para produzir resultados bons sanitários (ampliação do acesso, qualidade, resolutividade, participação social, etc), funcionar de forma integrada, de acordo com a situação demográfica e epidemiológica do território, nota-se que o desenho em curso em Natal tem distorçoes e vem produzindo resultados insatisfatórios.

É claro que isso está diretamente relacionado ao cenário político da gestão municipal (2009-2012), especialmente, da Secretaria Municipal de Saúde/SMS, que ao longo desses anos não só não investiu na qualificação e expansão da rede de saúde local, bem como desmantelou a rede e afundou os avanços conquistados nas gestões passada. A priorização gradativa da cessão da gestão de serviços públicos de saúde para as Organizações da Sociedade Civil de Interesse Público (OSCIPs) e terceirização do SUS na cidade de Natal foi outro aspecto que causou impacto negativo na medida em que muitos pontos da assistência à saúde passaram a ser negligenciados como o caso da atenção primária e psicossocial, da rede de urgência e emergência envolvendo UPAs e 
SAMU e os leitos de atenção integral, componentes imprescindíveis à abordagem das situações crônicas que requerem como ação de enfrentamento a continuidade de cuidados.

Em análise recente do cenário internacional e nacional, Mendes (2010) aponta que a maior dos países apresenta sistemas de saúde fragmentados, focados nas condições agudas, caracterizados por pontos que não se comunicam e incapazes de prestar uma atenção contínua à população. Diz claramente que "os sistemas fragmentados têm sido um desastre sanitário e econômico em todo o mundo" (Mendes, 2010, p.2299), pois carecem dos atributos fundamentais que caracterizam um sistema integrado e articulado em redes de saúde. Ele acrescenta que há "evidências de boa qualidade de que as redes de atenção à saúde podem melhorar a qualidade clínica, os resultados sanitários, a satisfação dos usuários e reduzir os custos dos sistemas de atenção à saúde" (Mendes, 2010, p. 2303).

No que diz respeito à saúde mental, sabemos que uma rede bem articulada, com coordenação entre os serviços e garantia de continuidade de cuidados necessita de integração em todos os âmbitos da saúde, incluindo as atenções primária, secundária e terciária, e articulação com as redes de caráter social, educativo, ocupacional, redes de cuidado informais, grupos de autoajuda, envolvendo usuários, suas famílias e as comunidades. Só assim poderemos diminuir as referências aos especialistas e hospitais psiquiátricos e superar o modo de atenção asilar, produtor de iatrogenia e exclusão social, na medida em que se tecem planos de cuidado que abarcam tanto a atenção ao portador de transtornos mentais, quanto ao seu entorno familiar e social.

Foi nessa direção, o Ministério da Saúde, através da Portaria 3088 de 23 dezembro de 2011(Brasil, 2011) instituiu a Rede de Atenção Psicossocial/RAPS como parte integrante da Rede de Atenção à Saúde do SUS, entendida como um conjunto de ações e serviços de saúde articulados em níveis de complexidade crescente, desenvolvidos em uma região de saúde que apresenta densidade tecnológica de gestão e cuidado, com a finalidade de garantir a integralidade da assistência numa perspectiva comunitária, territorial e longitudinal.

O componente da regulação e avaliação dos serviços está diretamente relacionado à qualificação das práticas de cuidado, de gestão e de funcionamento da rede de atenção psicossocial. Nesse sentido, se reconhece a necessidade de oferecer alguns elementos normativos, ou melhor, a definição de algumas linhas de 
cuidado (clínico e psicossocial) que contemplem a multidimensionalidade pessoal/subjetiva, territorial, cultural, de recursos, etc, que caracteriza o trabalho em saúde mental. Tal necessidade se apresenta como algo fundamental na atualidade, pois segundo Mângia e Muramoto é evidente que há uma "crise de operatividade" dos serviços de saúde mental que geralmente,

tendem a não responderem satisfatoriamente as demandas e necessidades dos usuários, apresentam uma organização fragmentada em procedimentos e competências das diversas corporações profissionais que os compõem, não desenvolvem ações territoriais, nem definem claramente prioridades assistenciais e níveis de responsabilidade sobre a população sob seus cuidados (Mângia \& Muramoto, 2009, p.120).

Além disso, complementam enfatizando que:

Tais avaliações também apontam para a dificuldade de criação de uma linguagem comum e compartilhada entre todos os atores que compõe as redes de serviços. Faltam, sobretudo, definição e compartilhamento de critérios e indicadores que possam subsidiar a caracterização e mensuração dos objetivos e resultados pretendidos e contribuir no processo de avaliação das novas redes e serviços (Mângia \& Muramoto, 2009, p.120).
Isso ficou evidente na realidade pesquisada. Quando questionamos nossos entrevistados acerca da função e articulação do seu serviço na RAPS, percebemos desarticulação, falta de clareza e de propostas comuns de trabalho. Identificamos assim problemas elementares no tocante à rede assistencial. Os discursos de que "a rede não existe; a rede é inoperante; não há integração", indicam uma dificuldade de conceber a rede não como algo etéreo e transcende, mas como uma malha viva de articulação entre atores que se comprometem, trocam conhecimentos e pactuam responsabilidades, logo, que todos fazem parte do cenário e são coparticipes.

Outro aspecto identificado é que para entrevistados há problemas com relação às definições das demandas atendidas por cada um, sobretudo no tocante à diferenciação entre "dependência química" e "transtorno mental", bem como em relação à territorialidade. Identificamos, portanto, três grandes problemas na organização dos serviços pesquisados: 1) Falta de consenso no sentido do que e quem deve ou não ser atendido no CAPS III; 2) Falta de acordos acerca do atendimento ao usuário que não possui registro no serviço, contato ou presença de familiares; 3) Equívocos em relação ao pertencimento territorial. Traduzindo em miúdos, o CAPS III, único 
em Natal, não tem porta aberta para as demandas em saúde mental, apenas para os moradores dos distritos leste e sul, além dos usuários vinculados ao CAPS Oeste. Não há atendimento de urgência para residentes do Distrito Norte, tal como anunciado anteriormente, onde reside parte da população que mais busca os serviços de saúde. Para eles resta o atendimento na Unidade de Pronto-atendimento deste distrito e o Hospital Psiquiátrico. Além disso, os casos de uso abusivo de álcool e outras drogas que chegam ao CAPS III são encaminhados para o CAPS AD em função do entendimento que a competência do serviço diz respeito somente aos casos de transtornos mentais graves. Nota-se, dessa forma, que há no CAPS III uma restrição importante em relação à demanda que pode ser atendida, sendo esse um dos componentes mais estratégicos da RAPS.

$$
\text { Nicácio e Campos (2004) }
$$

afirmam que a organização da rede assistencial com alta taxa de especialidade dos serviços resulta na reafirmação do lugar do hospital psiquiátrico como necessário no desempenho da função de internação. Sendo assim, o que deveria configurar-se como uma rede psicossocial articulada, funciona como circuito psiquiátrico, no qual as instituições funcionam em esquema de complementaridade, dividindo suas funções entre a atenção territorial (CAPS) e a internação (hospital psiquiátrico). Os autores concluem:

\begin{abstract}
A lógica seletiva de organização dos serviços, com base em sua própria competência, resulta em constantes reenvios da demanda a outras estruturas assistenciais, restrição e ausência de respostas aos problemas e sofrimentos das pessoas, desconhecimento das necessidades presentes no território e, sobretudo, desresponsabilização e abandono das situações e dos usuários considerados graves (Nicácio \& Campos, 2004, p. 73).
\end{abstract}

Não há dúvida que essa é a realidade identificada em Natal. O lugar que a crise ocupa na assistência revela uma crise nela própria no sentido de confrontar o limite de cada serviço em responder de forma resolutiva e eficiente a algo que demanda a criação de uma complexidade de instrumentos e ações por parte das equipes (Costa, 2007). Assim, observamos que o Hospital Psiquiátrico é o ponto de atenção mais requisitado da rede. Ele recebe casos oriundos de todos os outros serviços, na maior parte das vezes através do SAMU. O CAPS III, que deveria estar fortalecido nessa rede, ainda não tem conseguido atender uma demanda considerável de casos de urgência e produzir uma assistência diferenciada, com curta internação e continuidade de cuidados. Atuar como principal porta de entrada para casos de crise e diminuir o 
número de internações, iniciando um processo paulatino de substituição do hospital psiquiátrico, ainda não é uma realidade no município de Natal. O CAPS III tem conseguido, no máximo, ser uma estrutura acoplada ao hospital psiquiátrico, diminuindo sua superlotação e, portanto, colaborando na disponibilização de vagas. "Convivem com a internação, sem substituí-la, e acabam por confirmar sua necessidade" (Costa, 2007, p.97).

Diante deste quadro, entendemos a necessidade de novas diretrizes e organização do atendimento da crise local e nacionalmente, já que essa realidade não é privilégio de Natal, mas pode ser identificada no país como um todo. Nessa direção, algumas linhas estão em operação em nível mundial a fim de definir $\mathrm{e}$ consensuar pautas de atuação e responsabilidades de cada um dos pontos da rede de atenção que intervêm no processo e os mecanismos de coordenação entre eles a fim de evitar a fragmentação do cuidado e o desperdício de recursos. Além disso, nota-se um esforço em orientar as equipes quanto ao acolhimento, transporte adequado, critérios de hospitalização voluntária e involuntária, procedimentos durante a internação, orientação para contenção mecânica e farmacológica, critérios de alta, orientação à família durante e após episódio de crise e hospitalização, bem como direito dos usuários. Essas diretrizes combinadas com a indicação das alternativas de recursos terapêuticos e sóciocomunitários disponíveis no território do usuário, bem como orientações em relação ao plano de continuidade de cuidados, são estratégias para

(...) la puesta en práctica de actuaciones integradas em los mecanismos generales de respuesta a las situaciones de crisis, que propician uma visión menos estigmatizadora del paciente y su familia en los momentos, quizá más trágicos, del discurrir de la enfermedad, facilitándoles un mecanismo de respuesta accesible, sencillo y ágil que contribuye a dar una respuesta más serena y normalizada en esos momentos (Junta de Extremadura, 2005, p.8).

\section{b. Formas de acolhimento e cuidado ao usuário em crise}

De acordo com a Política Nacional de Humanização/PNH do Ministério da Saúde (Brasil, 2004):

O acolhimento é um modo de operar os processos de trabalho em saúde de forma a atender a todos que procuram os serviços de saúde, ouvindo seus pedidos e assumindo no serviço uma postura capaz de acolher, escutar e pactuar respostas mais adequadas aos usuários. Implica prestar um atendimento com resolutividade e responsabilização, orientando, quando for o caso, o paciente e a família em relação a outros serviços de saúde para a continuidade 
da assistência e estabelecendo articulações com esses serviços para garantir a eficácia desses encaminhamentos (Brasil, 2004, p.5).

Objetiva-se reverter os modos tradicionais de cuidado em saúde que se restringem a uma "ação pontual, isolada e descomprometida com os processos de responsabilização e produção de vínculo" (Brasil, 2004, p.7). Em relação ao cenário local no que diz respeito ao acolhimento ao usuário em crise confirmamos a ausência de critérios claros em termos das intervenções e distribuição de responsabilidades na RAPS, contrariando todas as diretrizes da PNH acima referidas.

$\mathrm{O}$ acolhimento à crise no CAPS II pesquisado está completamente condicionado à presença do psiquiatra no serviço. É unânime o discurso de que o CAPS II não é um serviço adequado para atender a crise, principalmente se o usuário não possui vinculo anterior com a equipe $\mathrm{e}$ procura atendimento sem acompanhante. A conduta da equipe é que após avaliação pelo psiquiatra, todo e qualquer usuário deve ser encaminhado para o hospital psiquiátrico ou para o CAPS III, indicando total ausência de hospitalidade nesses dispositivos. Caso esteja com acompanhante, esse se responsabiliza por chamar o SAMU para que se realize o atendimento e deslocamento. Sendo usuário do serviço, a justificativa para encaminhamento ao hospital psiquiátrico ou CAPS III gira em torno da falta de medicação, local apropriado para o atendimento e o fato do serviço não dispor de psiquiatra em todos os horários.

Esse quadro é preocupante. Não bastassem as restrições impostas pelo CAPS III, o acolhimento ofertado no CAPS II está praticamente restrito ao encaminhamento. A equipe não possui diretrizes terapêuticas para atender a demanda de crise, nem a espontânea, nem a de seus próprios usuários. Isso nos leva a questionar: esse serviço está de fato produzindo um encaminhamento responsável e resolutivo, conseguindo avaliar riscos e vulnerabilidades? Está conseguindo acolher com responsabilização já que sabemos que "as portas de entrada dos aparelhos de saúde podem demandar a necessidade de um grupo especializado em promover o primeiro contato do usuário com o serviço, como Pronto-socorro, Ambulatórios de Especialidades, Centros de Saúde, etc" (Brasil, 2004, p.16)? Isso significa que o acolhimento como ato ou efeito de acolher implica, em suas várias definições, uma ação de aproximação, um "estar com" e "perto de", ou seja, implica uma atitude de inclusão.

No SAMU, apesar de todas as dificuldades em termos das práticas em relação à crise, nota-se uma linha de ação 
mais definida e, portanto, uma clareza acerca do seu lugar na RAPS. Sua função tem sido a de direcionar de forma adequada o usuário na rede, distribuindo os casos entre os serviços disponíveis. Sem isso, toda a demanda do município iria para o HP. O SAMU faz a identificação da demanda, da área onde se encontra o usuário para definir o serviço mais próximo e adequado às necessidades, bem como realiza algumas orientações em termos de medicação e cuidados domiciliares. Em outras palavras, o SAMU tem cumprido um papel fundamental nessa rede de atenção de atendimento da crise, contribuindo para a articulação e definição de responsabilidades sanitárias de cada ponto de atenção.

Em relação ao CAPS III, serviço estratégico de atenção à crise 24 hs e único em Natal, atualmente conta 10 leitos (podendo acolher até 12 usuários). Como referido anteriormente, atende unicamente usuários do próprio serviço e moradores dos distritos sanitários sul e leste e usuários do CAPS Oeste. Em relação a esse serviço observamos grande demanda não acolhida por falta de suporte estrutural e técnico; processo de trabalho e de gestão sem definição clara das funções de cada um, sem coordenação e consenso quanto às formas de intervenção em relação à crise; precariedade da rede de atenção que faz com que o CAPS III não dê respostas satisfatórias e não consiga produzir uma atenção integral. A situação do CAPS III é a mesma apontada por Costa (2007) em relação às experiências internacionais cujas propostas eram desarticuladas, não davam respostas satisfatórias às necessidades dos usuários, com encaminhamento sistemático dos casos "porque não superavam o modelo cultural de referência ao hospital psiquiátrico como recurso de recepção dos "fracassos" dos serviços comunitários. Tal funcionamento acabava por manter a sustentação prática, técnica e ideológica do hospital" (p.98).

Já os CAPS AD têm limitações em relação à atenção do usuário com patologia dual; em situações de exacerbação da crise com intercorrências clínicas, de articulação com o CAPS III, bem como com o HP, que geralmente não dispõe de vagas na unidade de desintoxicação, enviando o usuário de volta ao CAPS AD. Por esse motivo, os profissionais tentam evitar o encaminhamento, dando suporte à crise dentro dos limites do serviço, encaminhando em casos excepcionais após avaliação criteriosa. Nesse ponto, os entrevistados relatam uma pactuação realizada com o Hospital Psiquiátrico, na qual os usuários do CAPS $\mathrm{AD}$ seriam recebidos com prioridade no hospital e vice-versa, porém com a mudança de gestão do HP, o acordo não vem sendo 
cumprido. Novamente, observa-se a fragmentação da rede e a não manutenção dos acordos no sentido de melhorar a assistência em saúde.

Observa-se que tanto nos casos dos hospitais gerais quanto das UPAs o que já foi detectado em outras realidades: "o uso excessivo de medicação e a polifarmácia, a utilização frequente de procedimentos de contenção, sem critério e monitoração, uma tendência a limitar o cuidado à clínica da supressão de sintomas" (Souza, 2012, p.6), além da falta de estrutura física e de capacitação dos recursos humanos, os quais são os elementos problemáticos que impedem o acolhimento das situações de crise de forma resolutiva e criação de novas modelagens de continência da crise, indicando a necessidade de reconfiguração da rede, de formação permanente desses profissionais e de divisão de responsabilidades entre estes serviços e os de cunho substitutivo. Em outras palavras, apresentam pouca capacidade de resposta em relação às demandas dos portadores de transtornos mentais e reafirmam um lugar para o manicômio na rede de atenção psicossocial.

Em relação ao hospital universitário, fica claro que apesar de contar com leitos de atenção integral em saúde mental, continua funcionando na lógica das especialidades clínicas e desenvolvendo um tipo de atenção não alinhada à perspectiva de reconfiguração dos hospitais gerais no contexto da reforma psiquiátrica. Em Natal, os seis leitos existentes no HU não podem ser ocupados por usuários em crise, mas apenas por aqueles que vêm encaminhados de outro hospital com alguma enfermidade que exige observação clínica. Por não consistir em porta de entrada para urgências, todos os usuários que buscam o $\mathrm{HU}$ e se enquadram no perfil de crise (transtorno e/ou uso de substâncias) são encaminhados para o hospital psiquiátrico. Sendo assim, conforme relato do gestor do serviço, os leitos de atenção integral são destinados apenas a usuários eletivos, que possuem algum tipo de comorbidade clínica associada ao transtorno mental, configurando-se num mecanismo de urgência referenciada, isto é, recebendo apenas usuários encaminhados de outras unidades hospitalares.

Esse quadro indica que estamos na contramão do que vem sendo proposto pela PNSM. Os hospitais gerais aparecem juntamente com os CAPS III e unidades de emergência, como dispositivos fundamentais na composição da rede de atendimento da crise, responsáveis, sobretudo, pelo acolhimento noturno de usuários que demandam cuidado emergencial (Dias, Gonçalves \& Delgado, 2010). Transformar os leitos de atenção 
integral em porta de entrada para as urgências e situações de crise consiste em um mecanismo efetivo para a garantia da acessibilidade, bem como tentativa de reversão do modelo asilar de atenção. Essa função não vem sendo cumprida pelo hospital universitário de Natal.

Em última análise, o HU não tem porta aberta à crise, logo, não faz parte da rede de suporte. Entretanto, o mais preocupante é o fato de que não há nenhuma problematização por parte dos gestores acerca do funcionamento desses leitos, muito menos proposições para mudança. Sabemos que a tendência mundial é o investimento em unidades de hospitalização breve, focalizadas na crise aguda e em intervenções terapêuticas intensivas a partir de um diagnóstico pluridimensional e orientadas por recomendações de atuação específicas quanto à contenção mecânica, farmacológica, etc. Essas unidades estão articuladas aos demais componentes da rede de atenção psicossocial para garantir a continuidade do tratamento no pós-alta com adequado planejamento de utilização dos recursos sanitários e sociais de acordo com as necessidades do usuário.

\section{Já o hospital psiquiátrico} constitui, indiscutivelmente, a porta de entrada para as situações de crise. Segundo os profissionais, os usuários que chegam ao HP, se encontram em "surto", intoxicados ou com síndrome de abstinência, hiperativos, agitados ou agressivos. Após o acolhimento e a avaliação médica, o usuário é medicado, podendo ser liberado ou ficar em observação, como ocorre na maioria dos casos. Esse processo varia de 24 à $72 \mathrm{hs,}$ que pode derivar para liberação ou internação. Em caso de permanência, o usuário é encaminhado para uma das enfermarias, sendo sua alta conferida por um clínico geral.

\section{c. Critérios diagnósticos para crise e internação}

Não há, entre os profissionais investigados, concordância quanto à definição de crise. Observa-se que os modos de reconhecimento da crise derivam das diferentes definições assumidas na prática de cada profissional. Concordamos com Costa que de modo geral, a crise e as tentativas de respostas às mesmas podem ser esquematizadas em torno das seguintes características:

- Exacerbação da noção de periculosidade ligada à pessoa em crise;

- Redução da experiência a sintomas e a comportamentos considerados "bizarros"; com tendência ao reconhecimento apenas de “traços" patológicos, anormais e insanos;

- Intervenções mais direcionadas à remissão dos sintomas em curto período de tempo; 
- Tentativa de normalizar e impor hábitos morais;

- Ênfase na negatividade da loucura e da crise; ênfase na desrazão, nas incapacidades e nas impossibilidades;

- Separação entre a crise e a vida global do sujeito;

- Uso frequente e mecanizado das contenções físicas, da eletroconvulsoterapia; uso generalizado e padronizado da medicação como recurso terapêutico mais importante ou prioritário;

- Ênfase no controle e na tutela; uso do espaço físico para contenção das crises; e Internação como recurso predominante (Costa, 2007, p.96).

Dell'Acqua e Mezzina (2004) apontam os parâmetros que os serviços podem utilizar para identificar as situações graves e que podem ser conduzidas para internação. São aquelas que obedecem, no mínimo, a três dos cinco parâmetros especificados: (1) grave sintomatologia psiquiátrica, (2) intensa ruptura no plano familiar e/ou social, (3) resistência ao tratamento, (4) recusa obstinada de contato, (5) incapacidade de enfrentar as situações de alarme surgidas em seu contexto de vida. Nas entrevistas realizadas, apenas o primeiro ponto foi destacado pelos profissionais da RAPS de Natal como critério de definição da crise psiquiátrica. Nenhum outro aspecto foi levado em conta que indique uma concepção ampliada das situações de crise, que é então reconhecida como um evento negativo que precisa de cuidados médicos intensivos com o objetivo de solucionar rapidamente a situação de agitação e/ou agressividade.

Essa concepção reducionista de crise define os modos de acolhimento na rede de Natal que são prioritariamente a medicação e a contenção, como apontadas anteriormente. Tal concepção não requer ações amplas, intensivas, flexíveis e singularizadas. Além disso, contribui diretamente para a entrada ou permanência dos usuários no circuito psiquiátrico, na medida em que são ações muito pontuais, focadas em sintomas, que não levam em conta a multidimensionalidade do problema. Assim, observamos crises frequentes e internações recorrentes com consequências nos processos de incapacitação e exclusão social dos usuários.

Outro aspecto preocupante é a inexistência de orientação em relação ao atendimento da crise. Há poucas concordâncias quanto às formas de acolhimento, aos critérios diagnósticos para identificação dos quadros de agudização do sofrimento psíquico e para aferição dos riscos apresentados pelos usuários como suicídio e condutas violentas. Contudo, a maioria dos entrevistados considera o médico como figura indispensável para avaliar a crise e 
decidir que condutas serão adotadas, indicando a presença de referências próprias ao modelo asilar em que o médico é o protagonista em detrimento do trabalho colaborativo, em equipe.

Portanto, ficou evidente a resposta padronizada diante da crise vivida de maneira tão distinta por cada usuário. Mesmo assim, questionamos se havia nos serviços orientação clara de como proceder diante dessas situações. Chegamos à conclusão que as equipes não têm clareza do que deve ser feito, cada uma faz aquilo que é possível no momento, não há nada que estruture o processo de trabalho, desconhecem recomendações básicas em termos de estrutura e funcionamento adequado dos serviços para atender crise, bem como em termos de contenção mecânica e farmacológica em caso de agitação, de intoxicação, de síndrome de abstinência, de psicoses, de transtornos psicorgânicos, transtornos de ansiedade e risco de suicídio. Essa desorientação não parece estar ligada à formação de categorias profissionais específicas ou ao tempo de trabalho, mas emerge como consequência da ausência de uma política contínua de ações coordenadas em diversos níveis e a fragilidade da rede de atenção que não tem diretrizes claras que orientem o cotidiano das equipes em relação aos recursos, intervenções, gestão dos serviços, hospitalização, coordenação do cuidado, atenção às famílias, inserção comunitária, dentre outros.

Esse quadro revela fatores de risco associados ao processo assistencial local, tal como indicado no Guía de Seguridad en la Atención a Personas con Trastornos Mentales organizado pela Consejería de Sanidad y Gerencia Regional de Salud de la Junta de Castilla y Leon, na Espanha. A ausência de protocolos específicos em termos de "evaluación general de riesgos; recogida y traslado seguro de pacientes; garantía de derechos en la hospitalización; evaluación e intervención en pacientes con riesgo de suicídio y autolesiones; atención a pacientes con riesgo de agitación, heteroagresividad $\quad \mathrm{y} / \mathrm{o}$ comportamentos antisociales; actuación ante pacientes con riesgo de fuga; actuación ante riesgo de accidentes/caídas; consentimiento informado; actuación ante pacientes con mala evolución; observación y vigilância" (Junta de castilla y leon, 2009, p.43), são aspectos que interferem na qualidade do processo assistencial.

Apesar das críticas procedentes quanto ao risco de se produzir padronização de condutas diagnósticas e terapêuticas, de se perder a singularização dos casos e do "traço artesanal" e de criatividade que o trabalho clínico precisa ter - como diz Campos e Amaral (2007, p.851) ao criticar os protocolos, fluxogramas, dentre outros procedimentos 
estandartizados de gestão - consideramos indispensável o estabelecimento de alguns norteadores ou linhas de cuidado pela necessidade de qualificar a atenção, de adotar modos mais eficientes de utilização dos recursos humanos e materiais e de garantir responsabilização clínica, eficácia e resolução das situações. Assim, esses norteadores podem funcionar como indutor de boas práticas e fator de proteção, seja na prática clínica, seja na gestão, seja junto aos usuários. Independente da importância e do potencial de tais protocolos, sua utilização deve estar atrelada a uma preocupação mais ampla quanto aos processos de trabalho. Ou seja, eles devem servir para promover mudanças e capacitação das equipes, criar parâmetros/indicadores para o funcionamento da RAPS e possibilitar o diálogo entre os serviços nas diferentes realidades do país.

\section{d. Recursos disponíveis e} dificuldades no atendimento da crise

Nos serviços substitutivos, ao serem interrogados a respeito de dificuldades no atendimento da crise, os profissionais apontaram a falta de educação permanente, de supervisão e apoio institucional. Além disso, indicam que a composição das equipes é feita de pessoas que não se identificam e não têm afinidade com o trabalho em saúde mental pelo fato de terem entrado via concurso público para a rede de saúde geral. Nas UPAs, a chegada do usuário em crise gera problemas para o serviço: tumulto nas dependências e para a própria equipe, é um usuário que requer mais atenção, gerando a necessidade de destacar um profissional para observação constante. É recorrente o discurso de que a UPA não é o local ideal para o atendimento da crise por não contar com um especialista em psiquiatria, ser carente de recursos materiais como leitos que permitam contenção e de insumos como medicamentos psicotrópicos. Os profissionais destacam a preocupação com a continuidade do cuidado, uma vez que o máximo que o serviço pode realizar é um atendimento paliativo. Nesse ponto, a questão da falta de articulação da rede, seja com os CAPS, seja com a atenção primária, é contemplada como a grande dificuldade para a continuidade da atenção e indicam problemas de acessibilidade na RAPS:

Um arranjo de serviço acessível permite que as pessoas não tenham que passar por esperas longas e burocráticas para avaliação e início de seu tratamento. O princípio da acessibilidade também deve garantir acesso a todas as pessoas que necessitem dos serviços, sem barreiras seletivas a grupos determinados (por diagnósticos, raça, grau 
de severidade ou quaisquer outros), além da disponibilidade em oferecer atendimento durante a noite e aos finais de semana (Mângia \& Muramoto, 2009, p.122).

Em relação ao $\mathrm{HP}$, os técnicos julgam que o volume de internações ultrapassa a capacidade de atendimento do hospital, produzindo um descompasso que vem se ampliando continuamente na adequação dos recursos humanos e materiais para atenção qualificada dessa demanda. As condições insalubres de tratamento são apontadas por todos os entrevistados: pacientes internados em leitos-chão, uso de lençóis rasgados para contenção; no pronto-socorro o número de técnicos é desproporcional ao de usuários (3 ou 4 profissionais são responsáveis pelo cuidado de 70 pessoas em intenso sofrimento psíquico); os leitos não contam com aparelhagem requerida aos demais hospitais para o atendimento emergencial de intercorrências clínicas; inexiste local para a acomodação dos acompanhantes, e o pouco e desorganizado espaço dificulta a circulação de técnicos e usuários. Ou seja, o HJM tem a clássica e conhecida arquitetura das instituições totais: baixa iluminação, longos e sujos corredores radiais, janelas gradeadas, poucos espaços individuais.

Os hospitais gerais, por sua vez, indicam como dificuldades a falta de recursos humanos qualificados e de estrutura adequada capaz de prover condições de segurança e privacidade para os usuários, técnicos e familiares acompanhantes. Tais fatores comprometem as condições de segurança requeridas ao acolhimento, tratamento e à realização dos procedimentos emergenciais de contenção.

Esses são exemplos claros daquilo que a literatura revela como fatores de risco associados à estrutura e funcionamento dos serviços.

Valoración de los factores ambientales y de equipamiento: carencia, inadecuación del equipamiento, mala conservación y mantenimiento del médio físico donde se lleva a cabo el proceso asistencial:

$\diamond$ Espacio: paredes, suelos, ventanas, puertas, etc., con medidas de protección ante caídas, golpes, incendios provocados o fortuitos.

$\diamond$ Facilidad de acceso: indicadores claros, $\sin$ barreras arquitectónicas que desorienten e impidan llegar a su destino de la forma más rápida a los usuarios.

$\diamond$ Luz: adecuada a la situación para la actividad y orientación de pacientes y trabajadores.

$\diamond$ Mobiliario: adecuado al espacio y situación, mínimo, confortable y seguro, que no pueda ser utilizado para actuar la hostilidade

$\diamond$ Instrumental y aparataje adecuados y no potencialmente lesivos, (por ejemplo contenciones mecánicas), así como custodia adecuada de material médico, de 
limpieza, etc. (Junta de Castilla y leon, 2009, p.42).

Apesar do pouco conhecimento de referências quanto à organização do espaço e adequação da estrutura física para o atendimento da crise entre os entrevistados, técnicos e gestores do hospital universitário, baseados em suas práticas cotidianas, apontaram importantes elementos nesse sentido: evitar o isolamento dos leitos de atenção integral em unidades específicas nos hospitais gerais e atenção redobrada em termos de vidraças, escadarias e objetos perfurocortantes. Em concordância, acredita-se que a integração dos leitos psiquiátricos às demais alas hospitalares pode auxiliar na desconstrução das estigmatizações dos usuários, contribuindo para que o hospital como um todo se torne um espaço de cuidado em saúde mental (Dias, Gonçalves \& Delgado, 2010). Por fim, destacaram o estabelecimento de espaços para acomodação dos acompanhantes. $\mathrm{O}$ indicativo da necessidade de locais destinados aos acompanhantes aponta para o reconhecimento da importância dos amigos e familiares na corresponsabilização do cuidado, seja na ampliação do processo diagnóstico por meio do fornecimento de informações acerca do contexto social e familiar do usuário, seja na participação das decisões terapêuticas e no acompanhamento do tratamento, em consonância com a Política Nacional de Humanização (Brasil, 2004), que para tanto propõe dispositivos como a visita aberta e o direito ao acompanhante em espaço hospitalar.

Problemas na qualificação da assistência representam importante desafio para a consecução do acesso e resolutividade no atendimento da crise. De maneira geral, o conhecimento sobre as diretrizes que orientam a RAPS e a experiência prévia no trato clínico das urgências psiquiátricas tende a produzir práticas de atenção voltadas para corresponsabilização dos usuários em crise. Entrevistados que relataram maiores dificuldades no emprego adequado das técnicas de contenção e condução emergencial do tratamento da crise foram aqueles cujas práticas restringiam-se ao encaminhamento intransitivo dos usuários para o hospital psiquiátrico.

A inexistência de qualquer programa educação permanente para o diagnóstico e acolhimento da crise faz parte do rol de dificuldades que estorvam a ação das equipes de saúde, sendo frequentes as dúvidas acerca dos critérios clínicos para o diagnóstico e caracterização dos quadros psicopatológicos, sobre etiologia, disfunções decorrentes, possíveis efeitos comórbidos e prognósticos 
esperados em função da gravidade dos sintomas identificados. Em outras palavras, os profissionais identificam problemas na realização do diagnóstico clínico e situacional, bem como dos riscos associados à condição do usuário. A essas dúvidas soma-se o desconhecimento acerca da legislação que rege a RAPS, suas diretrizes e financiamento, da disposição e dos modos de funcionamento da rede de saúde SUS como um todo.

Esse quadro tende a minar as estratégias para o manejo da crise, dificultando a adequação terapêutica dos recursos clínicos disponíveis às necessidades de cuidado dos usuários. Conforme descritas por Vasconcelos (2003), tais necessidades não se limitam à atenção aos agravos psíquicos decorrentes dos quadros de agudização psiquiátrica. Os profissionais dos serviços hospitalares precisam estar preparados para intervir junto às vulnerabilidades socioeconômicas das quais sofrem a grande maioria dos usuários. Além delas, precisam saber lidar com os conflitos de interesse e vínculos familiares patogênicos, com as consequências iatrogênicas dos longos períodos de internações anteriores e ainda com as limitações cognitivas e comunicacionais induzidas pelo próprio transtorno mental e pelos efeitos colaterais dos psicofármacos.
Ou seja, o manejo terapêutico das situações de crise exige de seus operadores uma revisão sistemática dos enrijecidos saberes e fazeres tradicionais. $\mathrm{O}$ elevado e multiforme sofrimento, as graves rupturas nos planos familiar e social e a irredutibilidade da experiência subjetiva a qualquer categoria ou conjunto de sintomas, demonstram o quão complexa é a situação de crise e o quanto devem ser complexos os instrumentos e recursos para respondê-la (Costa, 2007). De fato, por ser uma ocorrência imprevista de agravo à saúde, cuja intensidade pode oferecer perigo ao usuário, urge uma assistência imediata; todavia, configura-se como um momento particularmente vulnerável, de intensa fragilidade subjetiva, onde as condições de realidade se redistribuem de maneira brutal para o usuário, provocandolhe a fragmentação de seus sistemas de referência (Ferigato, Campos \& Ballarin, 2007).

Nesse sentido, uma qualificação contínua que englobasse toda essa complexidade no entendimento e no manejo da crise seria de fundamental importância, de modo a contemplar estratégias de intervenção eficazes. Do mesmo modo, a supervisão pode contribuir na orientação desse trabalho e também na escuta e busca de manejo das dificuldades enfrentadas pelos trabalhadores no atendimento da crise e estabelecimento de 
planos de seguimento e articulação com a rede de suporte. Quando não há uma política efetiva que garanta supervisão das equipes e educação permanente, como acontece na realidade investigada, observase uma fragilidade na consecução dos princípios da Política Nacional de Humanização (Brasil, 2004), a qual prevê a educação permanente dos profissionais da saúde como ferramenta crucial no incremento da qualidade da assistência, imprescindível não apenas pela qualificação e reciclagem profissional, mas do ponto de vista da valorização e do reconhecimento do trabalhador, assim como de suporte para que possa lidar melhor com a sobrecarga emocional e o desgaste gerado pelo trabalho. Estudo realizado por Sá (2005) junto ao segmento que atende emergências psiquiátricas observou o processo de trabalho na porta de entrada de um hospital de emergência em grande centro urbano do Brasil sob a ótica dos processos intersubjetivos presentes naquele serviço de saúde. A pesquisa revelou as estratégias defensivas dos trabalhadores para lidar com o sofrimento gerado pela complexidade de tal demanda:

o trabalho na Porta de Entrada da Emergência representa muitas fontes de sofrimento psíquico para os trabalhadores, como o dilema entre atender as urgências, em caráter estrito, e aliviar outros sofrimentos da população; a pressão para trabalhar mal; o risco de não identificar os casos de risco de vida; o lidar com a violência; e o não reconhecimento do bom trabalho, entre outras. Muitas estratégias de defesa utilizadas contra o sofrimento corroem, aliadas a outros fatores, os espaços para a solidariedade, a cooperação e o cuidado com a vida. Outras, no entanto, indicam que algum grau de ilusão e idealização com relação ao trabalho ainda subsiste e, junto com a busca por reconhecimento, podem abrir algumas brechas para a transformação do cotidiano dos serviços de saúde (Sá, 2005, p. 08).

\section{Considerações Finais}

Como referido no início desse trabalho, o atendimento da crise é um analisador privilegiado da capacidade de resposta da RAPS às demandas de saúde mental do ponto de vista da oferta e resolutividade, organização dos serviços, processo de trabalho, qualificação das equipes e educação permanente. A presente pesquisa revelou aspectos preocupantes nesse sentido na realidade do município de Natal. Identificamos em diferentes pontos da RAPS problemas referentes aos seguintes níveis:

- Estrutura e funcionamento dos serviços, recursos materiais $\mathrm{e}$ insumos disponíveis: rede precarizada do ponto de vista do 
número e distribuição dos serviços que acolhem crise; problemas de acessibilidade/porta aberta; estrutura física inadequada, carente de equipamentos e medicamentos; falta de integração dos componentes da RAPS entre si, especialmente com os serviços de atenção primária e dispositivos do território de pertencimento do usuário; configuração hospital-centrada.

- Composição e qualificação das equipes: reduzido número de profissionais disponíveis para cuidados intensivos, formação inadequada e ausência de processos de educação permanente visando à qualificação do cuidado e suporte ao trabalhador.

- Processo de trabalho e gestão: inexistência de linhas claras de cuidado e diretrizes sobre o manejo da crise; ausência de apoio institucional e supervisão do trabalho; sobrecarga de atribuições e falta de corresponsabilização dos diferentes dispositivos no atendimento da crise; centralidade na figura do médico e fragilidade nos processos coletivos de trabalho.

- Clínica e continuidade do cuidado: tripé do cuidado é constituído pela contenção, medicação e encaminhamento; dificuldades na realização de diagnóstico clínico e situacional, bem como dos riscos associados; ausência de planos de ação e tratamento imediato, assim como de seguimento articulado com a rede sociosanitária e familiar; falta de orientação às famílias sobre crise, cuidados e direitos dos usuários.

Dessa forma, consideramos que há pontos de estrangulamento na RAPS que impactam no atendimento da crise e indicam problemas na sua capacidade de resposta. Iniciativas em curso em outras realidades revelam que é preciso investir em estratégias que fortaleçam a aliança e o vínculo terapêutico, fundamentais para a prevenção de recaídas e re-internação. Nessa direção, os leitos em hospitais gerais, as instâncias de hospitalização breve que acolhem pequenos grupos, a articulação com os serviços de atenção primária para o manejo, detecção precoce e constituição da rede de suporte comunitário, o atendimento domiciliar e apoio intensivo à crise, são estratégias que podem impactar não só nos processos de acolhimento e cuidado do usuário, mas nos trabalhadores e familiares, reduzindo a sobrecarga e ampliando a corresponsabilização. Isso nos leva a concluir que Natal não apresenta, no momento, 
capacidade de responder às situações de crise e demandas emergenciais - dependente de uma boa articulação da SM com os demais serviços de saúde, especialmente de urgência e emergência e a presença efetiva de leitos de atenção integral em saúde mental (LAISM - CAPS III, HG, emergência em HG) - além de integração eficaz com rede de suporte social (Brasil, 2009, p.25).

\section{Referências}

Brasil. (2003). Ministério da Saúde. Política nacional de urgências. Portaria 1863/GM de 29 de setembro de 2003; Portaria 1864 de 29 de setembro de 2003 e a Portaria 2048 de 5 de novembro de 2002. Brasília: Ministério da Saúde.

. (2004). Ministério da Saúde. Núcleo Técnico da Política Nacional de Humanização. Humanizasus: acolhimento com avaliação $e$ classificação de risco: um paradigma ético-estético no fazer em saúde. Brasília: Ministério da Saúde. Disponível em http://bvsms.saude.gov.br/bvs/public acoes/acolhimento.pdf. Acesso em 15 de novembro de 2012.

. (2009). Ministério da Saúde. Secretaria de Atenção à Saúde. Saúde mental no sus: acesso, eqüidade, qualidade. Desafios para consolidar a mudança do modelo. Relatório de gestão 2008. Coordenação nacional de saúde mental, álcool e outras drogas. Brasília: Ministério da Saúde. Disponível em: $<\underline{\text { http://portal.saude.gov.br/portal/arq }}$ uivos/pdf/relatorio_gestao_sas_2008. pdf>. Acesso em 15 de novembro de 2012.

(2011). Ministério da Saúde. Saúde mental no sus: $\quad$ as novas fronteiras da reforma psiquiátrica. Relatório de gestão 2007-2010.

Coordenação nacional de saúde mental, álcool e outras drogas. Brasília: Ministério da Saúde. Disponível em: $<$ http://portal.saude.gov.br/portal/arq uivos/pdf/gestao2007_2010.pdf $>$.

Acesso em 15 de novembro de 12. - (2011). Ministério da Saúde. Portaria $n^{\circ} 3.088$, de 23 de dezembro de 2011. Institui a rede de atenção psicossocial para pessoas com sofrimento ou transtorno mental e com necessidades decorrentes do uso de crack, álcool e outras drogas, no âmbito do sistema único de saúde. Disponível em http://www.brasilsus.com.br/legislac oes/gm/111276-3088.html. Acesso em 15 de novembro de 2012. 
Brito, J. C. (2000). Enfoque de gênero e relação saúde/trabalho no contexto de reestruturação produtiva e precarização do trabalho. Cadernos de Saúde Pública, 16(1), 195-204. Disponível em: $<$ http://www.scielo.br/scielo.php?scri $\mathrm{pt}=\mathrm{sci}$ arttext $\& \mathrm{pid}=\mathrm{s} 0102-$

\section{$\underline{311 \times 2000000100020 \& \operatorname{lng}=p t \& \operatorname{lng}=}$} pt>. Acesso em 15 de novembro de 2012.

Campos, G. W. S., \& Amaral, M. A. (2007). A clínica ampliada e compartilhada, a gestão democrática e redes de atenção como referenciais teórico-operacionais para a reforma do hospital. Ciência \& Saúde Coletiva, 12(4), 849-859. Disponível em

$<$ http://www.scielo.br/scielo.php?scri $\mathrm{pt}=\mathrm{sci}$ arttext $\& \mathrm{pid}=\mathrm{s} 1413$ $\underline{81232007000400007 \& \operatorname{lng}=\text { en } \& \text { tlng }=}$ pt>. Acesso em 15 de novembro de 2012 ..

Comunidad de Madrid. Plan de atención social a personas com enfermedad mental grave y crónica 2003-2007, consejería de família y asuntos sociales, comunidad de madrid. Disponível em: http://www.mancomunidadtham.es/fileadmin/pdf/pdf39.pdf. Acesso em 15 de novembro de 2012.
Costa, M. S. (2007). Construções em torno da crise. Saberes e práticas na atenção em saúde mental e produção de subjetividades. Archivos Brasileiros de Psicologia. 59 (1), 94108. Disponível em: <http://seer.psicologia.ufrj.br/index.p hp/abp/article/view/38/54>. Acesso em 15 de novembro de 2012.

Dell'Acqua, G., \& Mezzina, R. (2004). Resposta à crise: estratégia e intencionalidade da intervenção no serviço psiquiátrico territorial. In P. Amarante. (Org.). Archivos de saúde mental e atenção psicossocial 2. (pp. 161-194). Rio de Janeiro: Nau.

Dias, M. K., Gonçalves, R. W., \& Delgado, P. G. G. (2010). Leitos de atenção integral à saúde mental em hospital geral: configuração atual e novos desafios na política de saúde mental. In E. M. Vasconcelos. (Org.). Desafios políticos da reforma psiquiátrica brasileira. (pp. 115140). São Paulo: Hucitec.

Ferigato, S.; Onoko-Campos, R.; Ballarin, M. L. (2007). O atendimento à crise em saúde mental: ampliando conceitos. Rev. Psicol. Unesp, 6(1), 31-44. Disponível em: <http://www.fcm.unicamp.br/laborat orios/saude_mental/artigos/atendime nto_ crise saude mental.pdf $>$. Acesso em 15 de novembro de 2012. 
Jardim, K. \& Dimenstein, M. (2007). Risco e crise: pensando os pilares da urgência psiquiátrica. Psicologia em Revista, Belo Horizonte, 13(1), 169190. Disponível em: $<$ http://pepsic.bvsalud.org/pdf/per/v1 $\underline{3 n 1 / v 13 n 1 a 11 . p d f}>$. Acesso em 15 de novembro de 2012 . (2008). A crise na rede: o serviço ambulatorial móvel de urgência (samu) no contexto da reforma psiquiátrica. Saúde em debate, v. 32, 150-160.

Junta de Extremadura. (2005). Protocolo de atención y traslado de la urgencia en salud mental. Consejería de sanidad y consumo. Espana. Disponível em http://www.saludmentalextremadura. com/fileadmin/documentos/protocolo _de_atencion_y_traslado_a_la_urgen cia.pdf. Acesso em 15 de novembro de 2012.

Junta de Castilla y Leon. (2009). Guia de seguridad em la atención a personas com transtornos mentales. Consejería de Sanidad. Gerencia Regional de Salud. Espana. Disponível em http://www.saludcastillayleon.es/insti $\underline{\text { tucion/es/bibliotecaonline/publicacio }}$ nes-consejeria/buscador/guiaseguridad-atencion-personas- trastornos-mentales. Acesso em 15 de novembro de 2012.

Lopes, M. J. M. \& Leal, S. M. C. (2005). A feminização persistente na qualificação profissional da enfermagem brasileira. Cadernos Pagu, 24, 105-125. Disponível em <http://www.scielo.br/scielo.php?scri $\mathrm{pt}=\mathrm{sci} \_$arttext $\&$ pid $=\mathrm{s} 0104-$ $\underline{83332005000100006 \& \operatorname{lng}=p t \& t \operatorname{lng}=}$ pt>. Acesso em 16 de setembro de 2012.

Luiz, R. R., \& Bahia, L. (2009). Renda e inserção profissional dos médicos brasileiros após instituição do sistema único de saúde. Rev. Saúde Pública, São Paulo, 43(4). Disponível em $<$ http://www.scielo.br/scielo.php?scri pt=sci_arttext\&pid=s0034$89102009000400016 \& \operatorname{lng}=$ pt\&nrm= iso>. Acesso em 16 de setembro de 2012.

Mângia, E. F.; \& Muramoto, M. T. (2009). Modelo de matriz: ferramenta para a construção de boas práticas em saúde mental comunitária. Rev. Ter. Ocup. Univ. São Paulo, São Paulo, 20(2), 118-125, maio/ago. Disponível em: http://www.revistasusp.sibi.usp.br/pd f/rto/v20n2/08.pdf. Acesso em 15 de novembro de 2012.

Mendes, E. V. (2007). Modelagem das Redes de Atenção à Saúde. Belo 
Horizonte: Secretaria de Estado de Saúde de Minas Gerais. Disponível em

<http://www.saude.es.gov.br/downlo ad/a_modelagem_das_redes_de_aten cao_a_saude.pdf $>$. Acesso em 15 de novembro de 2012.

. (2010). Como redes de atenção à saúde. Ciência \& Saúde Coletiva, 15 (5), 2297-2305. Recuperado setembro 18, 2012. Disponível em http://www.scielo.br/scielo.php?scrip $\mathrm{t}=\mathrm{sci} \_$arttext\&pid=s1413$81232010000500005 \& \operatorname{lng}=$ en $\& \ln g=$ pt. Acesso em 15 de novembro de 2010 .

Nicácio, F.; \& Campos, G. W. S. (2004). A complexidade da atenção. Rev. Ter. Ocup. Univ. São Paulo, São Paulo, 15(2), 71-81, maio/ago.

Organización Mundial de la Salud (OMS). (2011). Guía de intervención mhgap para los trastornos mentales, neurológicos y por uso de sustancias en el nivel de atención de la salud no especializada. Organización Mundial de la Salud, Departamento de Salud Mental y abuso de sustancias. Disponível em http://whqlibdoc.who.int/publications /2011/9789243548067_spa.pdf.

Acesso em 15 de novembro de 2012.

Pitta, A. M. F. (2011). Um balanço da reforma psiquiátrica brasileira: instituições, atores e políticas. Ciência \& saúde coletiva, 16(12), 4579-4589. Disponível em http://www.scielo.br/scielo.php?scrip t=sci_arttext\&pid=s1413-

\section{$\underline{81232011001300002 \& \operatorname{lng}=p t \& t \operatorname{lng}=}$} pt. Acesso em 15 de novembro de 2012.

Sá, M. de C. (2005). Em busca de uma porta de saída: os destinos da solidariedade, da cooperação e do cuidado com a vida na porta de entrada de um hospital de emergência. Tese de Doutorado. Instituto de Psicologia da Universidade de São Paulo. Departamento de Psicologia Social e do Trabalho.

Silva, A. A.; Rotenberg, L.; \& Fischer, F. M. (2011). Jornadas de trabalho na enfermagem: entre necessidades individuais e condições de trabalho. Revista de Saúde Pública, 45(6), 1117-1126. Disponível em: http://www.scielo.br/scielo.php?scrip

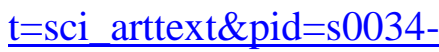
$\underline{89102011000600014 \& \operatorname{lng}=p t \& t \ln g=}$ pt. Acesso em 16 de setembro de 2012.

Schmidt, M. I. et al. (2011). Doenças crônicas não transmissíveis no brasil: carga e desafios atuais. The Lancet. Saúde no Brasil. (pp. 61-74). Disponível em 
http://portal.saude.gov.br/portal/arqui vos/pdf/revista_the lancet.pdf.

Acesso em 15 de novembro de 2012.

Souza, P. J. C. Serviço de urgência psiquiátrica de belo horizonte. Disponível em http://xa.yimg.com/kq/groups/22370 896/1330363327/name/servico_de_u rgencia_psiquiatrica\%5b1\%5d.pdf.

Acesso em 15 de novembro de 2012. Vasconcelos, E. M. (2003). O poder que brota da dor e da opressão: empowerment, sua história, teorias e estratégias. São Paulo: Paulus.

\footnotetext{
Magda Dimenstein: Doutora em Saúde Mental/UFRJ. Professora titular do Departamento de Psicologia. Docente do PPGPsi/UFRN. Bolsista de Produtividade do CNPq.

E-Mail: $\underline{\text { magda@ufrnet.br }}$
}

Ana Karenina Arraes Amorim: Doutora em Psicologia Social/UFRN. Professora Adjunta do Departamento de Psicologia/UFRN.

E-Mail: akarraes@ gmail.com

Jader Leite: Doutor em Psicologia Social/UFRN. Professor Adjunto do Departamento de Psicologia. Docente do PPGPSi/UFRN.

E-Mail: jaderfleite@gmail.com
Kamila Siqueira: Psicóloga. Bolsista de Apoio Técnico/CNPq

E-mail: kamsiqueira@gmail.com

Viktor Gruska: Discente de graduação em Psicologia/UFRN. Bolsista IC- PIBIC

E-mail: viktorgruska@gmail.com

Clarisse Vieira: Discente de graduação em Psicologia/UFRN. Bolsista IC- PIBIC E-mail: claclarissev@ hotmail.com

Cecília Brito: Discente de graduação em Psicologia/UFRN. Bolsista IC- PIBIC

Ianny Medeiros: Discente de graduação em Psicologia/UFRN. Bolsista IC- PIBIC E-mail: iannyfelinto@hotmail.com

Maria Clara Bezerril: Discente de graduação em Psicologia/UFRN. Bolsista IC- FAPERN

E-mail: clarinha_bezerril@yahoo.com.br 